\title{
Retraction Note: Relationship between water content, shear deformation, and elastic wave velocity through unsaturated soil slope
}

\author{
Yulong Chen ${ }^{1,2} \cdot$ Muhammad Irfan ${ }^{2,3} \cdot$ Taro Uchimura $^{2} \cdot$ Qingxiang Meng ${ }^{4} \cdot J^{\text {Je }}$ Dou $^{5}$
}

Published online: 6 September 2021

๑) Springer-Verlag GmbH Germany, part of Springer Nature 2021

Retraction Note to: Bulletin of Engineering Geology and the Environment (2020) 79:4107-4121

https://doi.org/10.1007/s10064-020-01841-8

The Editors-in-Chief have retracted this Article due to significant overlap with a previously published article (Chen et al. 2019).

Chen, Y., Irfan, M., Uchimura, T and Dou, J. agree to this retraction. Meng, Q. has not responded to any correspondence from the Editor/Publisher about this retraction.

\section{References}

Chen Y, Irfan M, Uchimura T (2019) Estimation of elastic wave velocity through unsaturated soil slope as function of water content and shear deformation. Soils Found 59(6):2180-2194. https://doi.org/ 10.1016/j.sandf.2019.12.001

The online version of the original article can be found at https:// doi.org/10.1007/s10064-020-01841-8

Yulong Chen

673054399@qq.com

$\triangle$ Jie Dou

douj888@vos.nagaokaut.ac.jp

1 School of Energy and Mining Engineering, China University of Mining and Technology, Beijing, China

2 Department of Civil Engineering, The University of Tokyo, Tokyo, Japan

3 Birudo Engineers, 107/C, PAF Officers Colony, Lahore, Pakistan

4 College of Water Conservancy and Hydropower Engineering, Hohai University, Nanjing, China

5 Department of Civil and Environmental Engineering, Nagaoka University of Technology, Niigata, Japan 